\title{
A Distinction Between Science and Philosophy
}

\author{
April 24, 2011
}

\begin{abstract}
Ever since Kant published his Critique of Pure Reason, most philosophers have taken the distinction between science and philosophy to depend upon the existence of a class of truths specially amenable to philosophical investigation. In recent times, Quine's arguments against the analyticsynthetic distinction have cast doubt over the existence of such a class of special philosophical truths and consequently many now doubt that there is a sharp distinction between science and philosophy. In this paper, I present a perfectly sharp distinction between science and philosophy which does not depend upon any distinction between philosophical and scientific truths.
\end{abstract}

For as long as analytic philosophy has existed, most analytic philosophers have believed that a sharp distinction between science and philosophy requires the existence of truths that can be known independently of scientific empirical investigation. Until fairly recently, it was widely supposed that such truths existed and that they were just the analytic truths: true by virtue of meaning alone, and hence discoverable by the analysis of meanings without the aid of empirical evidence. The belief that a sharply distinguishable philosophy requires a sharply distinguishable class of sentences discoverable by philosophical techniques, is so generally and firmly held among analytic philosophers that currently the field is divided between those who those accept Quine's arguments against the existence of analytic truths, and hold that philosophy is indistin- 
guishable from highly theoretical science, and those who maintain that philosophy can be distinguished from science on the grounds that a distinction can be drawn between scientific and philosophical truths (for examples of the latter see Boghossian 1996; Bealer 1996; Sher 1999; Hacker 2006 and Freidman 1993).

In this paper I argue that this common assumption is false, and that there is a perfectly clear and sharp distinction between philosophy and science that does not depend upon the existence of any truths other than those accessible by scientific empirical investigation. In particular, I argue that semantic holism, the central premise of Quine's arguments against the existence of analytic truths and a priori knowledge, implies that there is an absolutely sharp distinction between science and philosophy.

\section{Quine's arguments for rejection of the analytic- synthetic distinction}

The main purpose of this paper is not to provide an exegesis of Quine's holism or his arguments against the analytic-synthetic distinction, but to show that the existence of a distinction between science and philosophy is perfectly compatible with the lack of a distinction between philosophical and scientific truths. Since drawing this distinction depends only upon the claim that whole theories (or at least large parts thereof) have empirical content, a close examination of the other aspects of Quine's holism, such as the nature of observation sentences and the connections between sentences, is not required. However, the significance of the distinction I propose is more readily grasped given a sense of the importance of holism in Quine's arguments concerning the existence of an analytic-synthetic distinction and the continuity of science and philosophy. For Quine not only argues that holism implies both the lack of an analytic-synthetic distinction and the continuity of science and philosophy, but also that reductionism (the doctrine that individual sentences each have their own empirical content) implies that there is an analytic-synthetic distinction. If this last claim 
is correct (and the traditional account of philosophy as the field devoted to the discovery of analytic truths is otherwise acceptable) and, as I argue in this paper, holism implies the existence of a sharp distinction between science and philosophy, then both semantic atomism and semantic holism each imply that science and philosophy are distinct. If semantic atomism and semantic holism were known to constitute an exhaustive dichotomy of the semantics of natural languages this would be a conclusive reason for believing science and philosophy to be distinct. Even if semantic atomism and holism were not known to be an exhaustive dichotomy, we would still have good reason to believe that science and philosophy are distinct in the absence of a plausible alternative account of how our theories and assertions connect with empirical contents. At the very least, if Quine's arguments for the continuity of science and philosophy have semantic holism as an essential premise and it turns out that holism implies science and philosophy are distinct, then we would be left without any reason for supposing that science and philosophy are continuous.

Quine's argument from reductionism to the existence of an analytic-synthetic distinction is one of the few perfectly clear arguments in Two Dogmas: "as long as it is taken to be significant in general to speak of the confirmation and infirmation of a statement, it seems significant to speak also of a limiting kind of statement which is vacuously confirmed, ipso facto, come what may; and such a statement is analytic"(41). More generally, if individual sentences have meaning in isolation then it is significant to talk of pairs of sentences as being synonymous, and (as Quine suggests earlier in Two Dogmas) "analytic" might be defined as "synonymous with a logical truth". Provided sentences' meanings are fixed by the observations that confirm or infirm them, the two definitions are extensionally equivalent.

Quine's argument in the opposite direction, showing that the analytic-synthetic distinction requires individual sentences to have meaning in isolation, is far more obscure. It is clear however that Quine holds there to be some such connection, for he claims that the two doctrines are "at root identical". It is also clear 
that holism is supposed to have a key role in establishing this connection, for in Two Dogmas holism is offered as an explanation of the failure of the various attempts to draw the analytic-synthetic distinction that Quine considers. Beyond this however, there is no clear and uncontroversial interpretation of Quine's argument on this point. Hints of the nature of such an argument can however be found in Quine's other works. In Word and Object the failure of "inter-subjective stimulus analyticity" to serve as a definition of "analytic" is explicitly attributed to the fact that many sentences have empirical content only indirectly "through the mediation of associated sentences"(64). Also in Word and Object there is a suggestion that the slack that leaves our manuals of translation under-determined also under-determines our attributions of analyticity, for the master argument of Word and Object is that synonymy is ill-defined because translation (even within the home language) is under-determined and "the relation of intra-subjective sentence synonymy ... is interdefinable with another elusive notion of intuitive philosophical semantics: that of an analytic sentence". Finally, in Epistemology Naturalised, Quine explicitly states "the crucial consideration behind my argument for the indeterminacy of translation was that a statement about the world does not always or usually have a separable fund of empirical consequences that it can call its own"(82).

Though it remains somewhat speculative, Quine's hints suggest the course of an outright argument: holism entails that many sentences (the non-observational sentences) do not have empirical contents, as a result our scientific theories and our manuals of translation are under-determined; So under-determined that no adequate and empirically discernible distinction can be drawn between analytic truths and synthetic statements that all competent speakers resolutely hold true. Whether this is an argument that Quine intended is debatable, as is the question of whether the argument is any good. Both questions are however irrelevant to our current concerns. For the purpose of criticising Quine's arguments for the continuity of science and philosophy I propose to simply grant both holism and the lack of an analytic-synthetic distinction and show that a perfectly sharp 
and clear distinction between science and philosophy can yet be drawn. For the positive purpose of justifying belief in this distinction between philosophy and science however, it should be emphasised that the only claim upon which this distinction depends is that whole theories (or substantial parts thereof) are the minimal units having empirical content.

\section{Quine's argument from the lack of an analytic- synthetic distinction to the lack of a distinc- tion between science and philosophy}

In the introduction to Two Dogmas, Quine declares that one effect of abandoning belief in the empirical contents of individual sentences and the analyticsynthetic distinction is "a blurring of the supposed boundary between speculative metaphysics and natural science"(20), and the closing paragraphs of that paper contain Quine's closest approach to an argument for that claim:

Ontological questions, under this view, are on a par with questions of natural science. Consider the question whether to countenance classes as entities ... Carnap has maintained that this is a question not of matters of fact but of choosing a convenient language form, a convenient conceptual scheme or framework for science. With this I agree but only on the proviso that the same be conceded regarding scientific hypotheses generally. Carnap has recognised that he is able to preserve a double standard for ontological questions and scientific hypotheses only by assuming an absolute distinction between the analytic and the synthetic, and I need not say again that this is a distinction which I reject. The issue over there being classes seems more of a question of convenient conceptual scheme, the issue over there being centaurs, or brick houses on Elm Street, seems more a question of fact. But I have been urging 
that this difference is only one of degree, and that it turns upon our vaguely pragmatic inclination to adjust one strand in the fabric of science rather than another in accommodating some particular recalcitrant experience.

(Quine 1953, 45)

Provided one does not fully accept the consequences of holism and remains focused upon individual sentences, it is easy to understand why so many philosophers have been convinced that the continuity of science and philosophy is "an inevitable consequence" of the rejection of the analytic-synthetic distinction (see Rosenberg 2010; Caro 2007). Holism does imply that individual sentences cannot be divided into those which are true by virtue of meaning alone and those whose truth can only be determined with the assistance of empirical investigation. Hence there is no special class of sentences whose truth can be determined purely by contemplation of unempirical factors such as simplicity or form or meaning. So too, questions over the truth of individual sentences cannot be sharply divided into factual and non-factual and hence, assuming philosophical questions are non-[empirically]-factual, there is no sharp distinction between philosophical questions and questions whose resolution requires empirical investigation.

If holism is true then unempirical factors affect the distribution of truth values over the sentences of our language only diffusely. Factors such as linguistic propriety, communicative use, and perhaps simplicity, may dominate in determining the truth value assigned to sentences distantly connected to experience by chains of mediating sentences. In principle however, the truth value assigned to any sentence, however remotely connected to experience, may be revised on empirical grounds; and any truth that is not absolutely and directly connected to observation may be revised on grounds such as simplicity or linguistic propriety.

From the lack of a distinction between sentences whose truth can be determined purely by unempirical philosophical investigation, and sentences whose truth can only be discovered with the aid of empirical investigation Quine, and 
many following him, inferred the lack of a sharp distinction between science and philosophy. As we shall see in the next section however, this inference is itself a vestige of the doctrine that individual sentences have empirical content in isolation.

\section{Distinguishing philosophy and science}

Despite superficial appearances holism, and the consequent rejection of analyticity, do not blur the distinction between philosophy and science. While holism does imply that disputes over the truth of individual sentences cannot be divided into scientific and philosophical disputes, that is only because holism implies disputes are never over the truth of individual sentences at all.

Holism is the doctrine that the minimal units of content are whole theories, and the minimal units of content are ipso facto the minimal units of dispute. If, as Quine declared, holism implies that any sentence can be held true in the face of any experience provided one is prepared to make drastic enough adjustments elsewhere in one's theory, then it also implies that one can only have reason to hold any individual sentence true or false against a background theory, and never purely in isolation. When Quine's exuberant claim is moderated to take observation sentences into account, the point goes through mutatis mutandis. One can have reason to prefer one theory over others and hence to hold its individual members true, but the only reason for holding any individual sentence not directly connected to experience true is because it is a member of a plausible theory. A question over the truth of any sentence which does not possess its own empirical content is never a question of the truth of that sentence in isolation, but always a matter of choosing between theories that contain the sentence in question and theories that do not.

Holism implies that it makes no sense to say that two statements have identical empirical contents (except perhaps for observation statements) since according to holism (most) individual sentences do not have any empirical contents at 
all. However, since holism is the doctrine that whole theories do have empirical contents, it also implies that it does make sense to say that two whole theories have identical empirical contents. Though there is no distinction to be drawn between statements in which belief can be justified on purely linguistic grounds and those in which belief must be justified (if justified at all) on empirical grounds; there is a distinction between disputes obtaining between empirically distinct theories, and disputes obtaining between empirically equivalent theories. Since empirical scientific investigation is irrelevant to disputes between empirically equivalent theories, scientific disputes are of the former kind; and, assuming that philosophy is an unempirical discipline (an assumption revisited in $\S 6)$, philosophical disputes are of the latter, to be resolved on unempirical grounds such as linguistic propriety, clarity, and perhaps simplicity. Furthermore, since identity is the ne plus ultra of relationships that do not admit of degree, this distinction between empirical and unempirical disputes is perfectly sharp.

Given knowledge of only a handful of the sentences in contention, it is usually impossible to conclusively determine whether a dispute is empirical or unempirical. If two English speakers disagree over the truth of "There are brick houses on Elm Street", we reasonably suspect their dispute is empirical, but the suspicion is defeasible. If we discover their dispute also extends to the truth of statements such as "There are physical objects" or "The Local council has the authority to name streets" we may well revise our own theory and judge their dispute to be unempirical. On the other hand hearing two English speakers disagree over the truth of "There are concepts" can justify the suspicion that their dispute is unempirical. Partly this is because concepts are notoriously disconnected from empirical evidence, but it is also because the proponents of concepts generally take concepts to be fundamental to explaining forms of human behaviour that nearly all English speakers would predict. We who are familiar with such disputes readily suspect that the argument will turn on the adequacy of each parties' explanation of human behaviour, rather than the accurate description 
of the behaviour they seek to explain. Still these justifications are far from conclusive. If, for instance, it turned out that both parties accepted some explicit neuro-physiological account of concepts, their dispute would be empirical after all.

So long as only some of the sentences in contention are known, it is usually impossible to clearly distinguish unempirical from empirical disputes. But the lack of clarity is due to ignorance rather than any imprecision in the distinction between empirical and unempirical disputes. When the revisions each party requires of the other's theory are fully specified, it is clear whether the dispute falls on the scientific or philosophical side of the divide. Scientific disputes involve revision of empirical content and may be settled by empirical investigation, philosophical disputes involve no such revision and empirical investigation is irrelevant to their resolution.

\section{Two Objections}

It may yet be objected that the distinction I have attempted to draw is less than perfectly clear because there is no decision procedure for determining whether two theories are empirically equivalent. If the theories in question are couched in quantificational calculus, or some notation that is at least equally complex, then the task of determining whether they have the same empirical consequences is equivalent to that of determining that two given Turing machines compute the same function. This latter task is well known to be undecidable, in the sense that no one method is sufficient to determine in every case whether or not two given theories are empirically equivalent. Still, there is no block to showing in particular cases whether or not two theories are empirically equivalent and, more importantly, any pair of theories is equivalent or not regardless of our ability to show it. The line between science and philosophy may be hard to draw, and we may go indefinitely long without being able to determine of a particular case just which side of the line it falls, but this does not imply that the 
distinction is not perfectly sharp. The lack of a decision procedure for empirical equivalence is simply a consequence of the well known fact that there is no decision procedure for determining theoremhood in quantificational theories. Just as the lack of such a decision procedure does not cast any doubt over the clarity of the distinction between theorems and other sentences, neither does the lack of a decision procedure for empirical equivalence cast any doubt over the distinction between empirically equivalent theories and empirically distinct theories.

Another objection may be raised against the clarity of the proposed distinction between science and philosophy on the grounds that no two disputants ever hold theories that are exact empirical equivalents. Each of us views the world from a slightly different point of view, has had access to observations that no one else is privy to and consequently holds different expectations of future observation. So it is that no dispute is ever completely free of empirical differences and, though purely philosophical disputes may exist as a philosopher's idealisation, in practice all disputes are to some extent empirical. Thus, the objection continues, we must either recognise all disputes as scientific, or, if sense can be made of the extent or importance of empirical difference between two theories, recognise that in practice the difference between philosophical and scientific disputes is only a matter of degree.

Though this objection is not without some merit, it is both uncharitable and misplaced. In describing the distinction between science and philosophy I talked of disputes concerning a single choice between theories. In practice however, even the most dogmatic protagonists demand less than wholesale acceptance of their theories, and sincere disputes between two parties usually involve four theories: the two theories the parties believe before their dispute, and the theories each party would hold if they made the modifications advocated by the other. Each party faces a choice over whether to hold to their original theory or to adopt the suggested modifications. Such disputes may thus be regarded as being composed of two disputes of the special sort I talked of earlier (of 
which either one, none, or both may be between empirically equivalent theories). In any case, what really matters is the revisions we make in our theories, whether as a result of private reflection, new observation, or the arguments of others. Sometimes we revise our theories, and in doing so change our empirical expectations, sometimes we revise our theories without any change in our empirical expectations and it is only some of these revisions that are properly philosophical.

\section{Mathematics}

One of the great hopes of early analytic philosophy was to show that mathematical truths were analytic, thereby explaining how knowledge of such truths could be gained without reliance on either empirical evidence or supra-empirical intuition. Holism, and the consequent rejection of the analytic-synthetic distinction, is of course incompatible with the realisation of such hopes. While holistic empiricism implies that both empirical and unempirical factors have a part to play is justifying the allocation of truth values to sentences, it also implies that the justification for holding any sentence true depends ultimately upon the merits of the empirical theories of which that sentence is a member. There is thus no special class of sentences in which belief is justified solely on unempirical grounds.

Critics have taken holism's failure to ascribe any special status to our knowledge of mathematical truths to be a defect. Our knowledge of truths of mathematics, they proclaim, is obtained by proof not experiment, and hence must be a priori; thus holism must be false if it implies there is no a priori knowledge (see Freidman 1993; Hacker 2006). Holism's proponents have responded by claiming that mathematical truths have empirical content, insofar as any theoretical sentence can, by virtue of being indispensible supports of our physical theories' empirical contents. While this response is a clear statement of holists' position, it does little to address the critics' observation that empirical evidence 
is generally irrelevant to disputes over the truth of mathematical claims.

One of the advantages of recognising the distinction between empirical and unempirical disputes, is that it allows us to reconcile holism with the premise of the critics' objection. For the belief that mathematical truths must be known a priori because they are established by proof rather than empirical investigation is, like belief in the continuity of science and philosophy, a remnant of the assumption that individual sentences have content in isolation. So long as that assumption is made, the irrelevance of empirical evidence to the resolution of the (final) dispute by which a mathematical claim is established will naturally be taken as a sign that empirical evidence is irrelevant to that claim's truth. Once that assumption is rejected however, and the distinction between empirical and unempirical disputes is recognised, we are free to recognise both the plain truth that disputes which center on mathematical claims are generally over a choice between empirically equivalent theories, and that it is in large part because the theories under consideration are required to support complex empirical contents that failure to contain the requisite mathematical truths renders them (unempirically) inferior.

In recognising that mathematical truths are generally established by the resolution of unempirical disputes, we concede that the line between empirical and unempirical disputes does not delineate philosophy uniquely (unless we are prepared to count all of pure mathematics as a branch of philosophy) for we have counted both philosophy and pure mathematics as lying on the unempirical side of the divide. This is not, however, to deny that this distinction sharply divides philosophy from science, but only to admit that philosophy is not the only unempirical discipline.

According to the view I am urging mathematical truths are not necessary, except in the vegetarian sense that it is difficult to imagine a world so simple that it could be completely described without the aid of mathematics, nor are they knowable strictly a priori. In a sense however, mathematical truths can still be counted as self-evident, for the existence of a creature complex enough 
to entertain such beliefs is in itself sufficient to ensure that any adequate empirical theory of the world including that creature will be complex enough to require mathematical support. Furthermore, to return to our main topic, on this view mathematical knowledge still serves as a valuable inspiration to philosophers. The question over the nature of the grounds for preferring some theories over their empirical equivalents is so large and controversial, and the answers philosophers currently advocate are so diverse, that I have not addressed it in this paper. In the absence of any accepted account of such grounds, mathematician's and logician's discoveries provide vital examples of substantive and important truths discovered (at the end) through the resolution of unempirical disputes, and the proofs by which their discoveries are vindicated are still to be reckoned as archetypal examples of the means by which unempirical disputes may be resolved.

\section{Conclusion}

Though I have been arguing against Quine's claim that the distinction between science and philosophy is only a matter of degree, I share his misgivings about the existence of a "first philosophy" which proceeds by unempirical means to discover truths known with greater certainty than those known through experience. Indeed my main purpose has been to show that there can be significant and productive disciplines devoted to the pursuit of knowledge by unempirical means which are not first philosophies. Whether a claim is held true as a result, at the last step, of a revision that does not involve altering empirical expectations is only a matter of historical accident, and the class of statements adopted by such means varies from one individual to another. Any statement, apart from those directly connected to observation, may be held true as a result of a revision that leaves empirical content unchanged. Conversely, by the same token, any statement however remotely connected to experience may be adopted because of its role in supporting some newly made observation. 
Philosophy, on the view I am advocating, is not distinguished from science by its subject matter but by its techniques. This is not to say that philosophy relies upon special techniques for resolving disputes or justifying changes in belief. The same techniques and considerations by which philosophers resolve their disputes also have a part to play in shaping our scientific theories and forming our empirical expectations. What distinguishes philosophy from science is that it is restricted purely to the use of those techniques; philosophers rely solely upon unempirical considerations to justify choosing between one theory and another, while scientists and more practically minded theorists also avail themselves of experiment and observation. It is this that justifies the conceit that philosophy has a special role to play in illuminating and developing our ability to reason. For just as scientists often arrange their experiments so as to hold some variables constant to better investigate the relationships between others, so too holding the empirical content of our theories fixed and looking solely to unempirical grounds for choosing between theories can help us to better understand the unempirical constraints upon our theories. Novices have the opportunity to develop their ability to recognise unempirical grounds for preferring some theories over others by focusing upon that skill in isolation, while experts may gain a sense of the limits of pure reason, the scope for human invention in our empirical theories, and the comparative merits of different forms of construction.

I have not directly addressed the issue of whether all the forms of enquiry that deserve the title "philosophy" are unempirical. That question might be dismissed as purely administrative, a matter of concern only to deans and librarians, though is it noteworthy how well the traditional objectives of analytic philosophy survive the transition to taking whole theories, rather than individual sentences, as the minimal units of content. The distinction between science and unempirical disciplines, under whatever name, is however no mere administrative boundary. By respecting this limit and pursuing the unempirical disciplines, though we do not gain access to any truths beyond those obtainable 
by empirical enquiry, we can gain a better sense of the roles of reason and evidence in shaping our empirical theories. Even in acknowledging this distinction we recognise that there is scope for the pursuit of knowledge by reason alone without the existence of truths of reason.

\section{Works Cited}

Bealer, George. "On the possibility of philosophical knowledge." Nous 30 (1996): 1-34.

Boghossian, P.A. "Analyticity reconsidered." Nô̂s 30 (1996): 360-391.

Caro, M.D. "The Claims of Naturalism." Explaining the Mental: Naturalist and Non-Naturalist Approaches to Mental Acts and Processes. . Newcastle: Cambridge Scholar Publishing, 2007. 222-237.

Freidman, M. "Philosophical naturalism." Proceedings and Addresses of the American Philosophical Association. . Volume 71 . American Philosophical Association, 1993. 5-21.

Hacker, P.M.S. "Passing by the Naturalistic Turn: On Quine's Cul-de-Sac." Philosophy 81 (2006): 231-253.

Quine, W.V. "Two Dogmas of Empiricism." From a Logical Point of View. . Reprint 1999, Harvard University Press, 1953. chapter 2, 20-46.

Quine, W.V. Word and Object. MIT Press, 1960.

Quine, W.V. "Epistemology Naturalized." Ontological Relativity \& other essays. . New York: Columbia University Press, 1969. chapter 3, 69-90.

Rosenberg, A. "Naturalistic Epistemology for Eliminative Materialists." Philosophy and Phenomenological Research 59 (2010): 335-358.

Sher, G. "Is There a place for Philosophy in Quine's theory." The Journal of Philosophy 46 (1999): 491-524. 